\title{
Methodology as a Lingua Franca in International Relations: Peripheral Self-reflections on Dialogue with the Core
}

\author{
Ersel Aydinli* \\ Ersel Aydinli is Professor of International Relations at Bilkent University. \\ *Corresponding author. Email: ersel@bilkent.edu.tr.
}

\begin{abstract}
Scholarly dialogue between 'core' and 'periphery' or 'West/non-West' in many disciplinary communities has become an issue of discussion in recent decades, spawned in part by increased expectations in many periphery communities of being published in core journals, and complicated by factors such as the linguistic hegemony of English and concerns about access. The International Relations (IR) discipline has been at the forefront of this discussion. However, despite widespread awareness of the issue, and a dedicated push for greater emphasis on local theorising out of the periphery, the cutting edge of global IR scholarship still remains core dominant. This article proposes that a focus on 'quality' methodology, in the broadest possible sense of having transparent and effectively applied research designs, could serve as a lingua franca to promote the exchange of ideas in a way less prone to disadvantage periphery scholars. The article goes on to examine this issue by focusing on the case of the Turkish IR disciplinary community. It looks at how methodological issues are currently considered in Turkish IR pedagogy and scholarship and then offers a self-reflective assessment of the quality of methodology in Turkish IR. It concludes by offering suggestions on how the Turkish IR disciplinary community could better address methodological issues and, ultimately, perhaps achieve greater impact within the global IR community.
\end{abstract}

\section{Introduction}

Several years ago I collaborated with two colleagues on writing a book whose main argument was that development of the International Relations (IR) discipline in the periphery could best be achieved by encouraging theory building. We proposed that, as an emerging disciplinary community, we needed to strengthen our local disciplinary core through theorising based on local phenomena, history, and experiences, in other words, 'homegrown' theorising. Our position reflected an underlying assumption that many IR scholars share: As an academic discipline, 
IR is dominated by the core. Core dominance within IR has been debated and discussed for decades. ${ }^{1}$ Its nature has been explored extensively through studies of both publishing ${ }^{2}$ and pedagogical practices. ${ }^{3}$ Although a few have argued that the discipline is actually more plural than widely recognised, ${ }^{4}$ or that core dominance doesn't really matter, ${ }^{5}$ the idea of an imbalance in the discipline is largely unquestioned. Moreover, despite increased awareness of this issue in recent years, in practice there has been no reduction of this dominance. ${ }^{6}$

A further common assumption is that core domination of the disciplinewhether it be through published and cited scholarship in leading journals, or in constituting the primary material used for teaching IR at universities-is connected to theory. The periphery is seen as failing to make, or as being prevented from making, meaningful contributions to the scholarly development of IR

1 Amitav Acharya, 'Advancing Global IR: Challenges, Contentions, and Contributions', International Studies Review, Vol. 18, No. 1 (2016), pp. 4-15; Robert M. A. Crawford and Daryl S. Jarvis, eds., International Relations-Still an American Social Science? Toward Diversity in International Thought (Albany: State University of New York Press, 2001); Stanley Hoffmann, 'An American Social Science: International Relations', Daedalus, Vol. 106, No. 3 (1977), pp. 41-60; Steve Smith, 'The Discipline of International Relations: Still an American Social Science?', British Journal of Politics and International Relations, Vol. 2, No. 3 (2000), pp. 374-402; Arlene B. Tickner and Ole Wæver, eds., International Relations Scholarship around the World (London: Routledge, 2009); Ole Wæver, 'The Sociology of a Not So International Discipline: American and European Developments in International Relations', International Organization, Vol. 52, No. 4 (1998), pp. 687-727.

2 For example, Peter M. Kristensen, 'Revisiting the "American Social Science": Mapping the Geography of International Relations', International Studies Perspectives, Vol. 16, No. 3 (2015), pp. 246-69.

3 For example, Julia Lau Bertrand and Ji-Young Lee, 'Teaching IR to a Multicultural Classroom', International Journal of Teaching and Learning in Higher Education, Vol. 24, No. 1 (2012), pp. 128-33; Jeff D. Colgan, 'Where is IR Going? Evidence from Graduate Training', International Studies Quarterly, Vol. 60, No. 3 (2016), pp. 486-98; Jonas Hagmann and Thomas J. Biersteker, 'Beyond the Published Discipline: Toward a Critical Pedagogy of International Studies', European Journal of International Relations, Vol. 20, No. 2 (2014), pp. 291-315.

4 Helen L. Turton, International Relations and American Dominance: A Diverse Discipline (New York: Routledge, 2016).

5 John Mearsheimer, 'Benign Hegemony', International Studies Review, Vol. 18, No. 1 (2016), pp. 147-9.

6 Daniel Maliniak, Susan Peterson, Ryan Powers and Michael J. Tierney, 'Is International Relations a Global Discipline? Hegemony, Insularity, and Diversity in the Field', Security Studies, Vol. 27, No. 3 (2018), pp. 448-84; Isaac Odoom and Nathan Andrews, 'What/Who is Still Missing in International Relations Scholarship? Situating Africa as an Agent in IR Theorizing', Third World Quarterly, Vol. 38, No. 1 (2017), pp. 42-60; Arlene B. Tickner, 'Core, Periphery and (Neo)Imperialist International Relations', European Journal of International Relations, Vol. 19, No. 3 (2013), pp. 627-46. 
theory, ${ }^{7}$ because neither teaching nor scholarship in much of the periphery places emphasis on it. ${ }^{8}$ Even in places where theory is considered a valued part of professional activity, therefore, the roles of periphery scholars are confined to 'importers', 'appliers', or 'native informants', rather than producers. ${ }^{9}$ They hence remain in a secondary position within the discipline. ${ }^{10}$ Although there are efforts in parts of the periphery to counter this existing imbalance, ${ }^{11}$ ultimately, privileged discourse within the IR discipline remains 'centred around American ... theoretical IR journals'. 12

Looking at these two assumptions after nearly 20 years of observing the discipline from academic contexts in both the North American core and the beyondEuropean periphery, I remain convinced that periphery contributions to the global IR disciplinary community still remain well below what they should be, and that the distribution of academic labour in IR continues largely to relegate periphery scholars to the role of consumers of core knowledge. However, I am no longer convinced that an emphasis on theory is the correct first step to righting this imbalance. In fact, I arguably perpetuated the problem through my earlier criticisms of the periphery's overemphasis on importing Western theories and assimilating into Western theoretical paradigms and my subsequent recommending of local theorising as the route to disciplinary development. While we still need to seek ways of

7 Amitav Acharya and Barry Buzan, 'Why Is There No Non-Western International Relations Theory? An Introduction', International Relations of the Asia-Pacific, Vol. 7, No. 3 (2007), pp. 287-312; Kal J. Holsti, The Dividing Discipline: Hegemony and Diversity in International Theory (London: Allen and Unwin, 1985).

8 Fernando Barasuol and Andre Luiz Reis da Silva, 'International Relations Theory in Brazil: Trends and Challenges in Teaching and Research', Revista Brasileira de Política Internacional, Vol. 59, No. 2 (2016), pp. 1-20.

9 Chen Ching-Chang, 'The Absence of Non-Western IR Theory in Asia Reconsidered', International Relations of the Asia-Pacific, Vol. 11, No. 1 (2011), pp. 1-23; Peter M. Kristensen, 'How Can Emerging Powers Speak? On Theorists, Native Informants and QuasiOfficials in International Relations Discourse', Third World Quarterly, Vol. 36, No. 4 (2015), pp. 637-53; Walter D. Mignolo, 'Epistemic Disobedience, Independent Thought and Decolonial Freedom', Theory, Culture and Society, Vol. 26, No. 7/8 (2009), pp. 159-81.

10 Anna M. Agathangelou and L. H. M. Ling, 'The House of IR: From Family Power Politics to the Poisies of Worldism', International Studies Review, Vol. 6, No. 4 (2004), pp. 21-49; Jorg Friedrichs and Friedrich Kratochwil, 'On Acting and Knowing: How Pragmatism can Advance International Relations Research and Methodology', International Organization, Vol. 63, No. 4 (2009), pp. 701-31; Wiebke Wemheuer-Vogelaar, Nicholas J. Bell, Mariana N. Morales and Michael J. Tierney, 'The IR of the Beholder: Examining Global IR Using the 2014 TRIP Survey', International Studies Review, Vol. 18, No. 1 (2016), pp. 16-32.

11 For example, L. H. M. Ling, 'Journeys Beyond the West: World Orders and a 7th Century Buddhist Monk', Review of International Studies, Vol. 36, No. S1 (2010), pp. 225-48.

12 Peter M. Kristensen, 'Dividing Discipline: Structures of Communication in International Relations', International Studies Review, Vol. 14, No. 1 (2012), p. 32. 
building up the IR discipline in the periphery, perhaps we should be prioritising something different.

The first step may be to reconsider the reasons behind the ongoing failure to establish effective core-periphery dialogue in IR, and the subsequent imbalanced representation of periphery ideas and scholarship in the IR discipline. As noted above, such reasons can no longer be attributed to lack of consciousness, as core awareness of the issue has reached heightened levels. Academic debates aimed at correcting the scholarship imbalance have investigated the merits of, and ideal conditions for, effective core-periphery dialogue. ${ }^{13}$ There have also been apparently genuine efforts in recent years to better integrate periphery IR voices into core discussions. Ongoing global IR discussions ${ }^{14}$ provide both an ideal ground to assess the existing periphery contributions to the IR discipline, ${ }^{15}$ while also encouraging the development of original, alternative IR theorising from the core. ${ }^{16}$ Meanwhile, institutional steps to amplify IR voices from the periphery have ranged from the introduction of disciplinary association groups focused on periphery IR issues, such as the International Studies Association's Southern Caucus, to the practice among some core IR journals of offering scholars free language editing services for successful submissions.

It can also be confidently stated that the representation imbalance does not stem from any lack of potential idea generation in the periphery. Much of the activity that the IR discipline concerns itself with, such as state revisionism, non-state actors, or broad issues of war and peace, is occurring most vividly in the periphery. This is no recent phenomenon. Today's 'periphery' often has a much longer history than do 'core' countries with the activities that gave birth to many IR practices and concepts, from war and peace to alliances and political economy. Yet although these were, in a sense, invented and mastered in what is now considered the periphery, few, if any, have been (re)conceptualised from periphery perspectives. There can be no doubt about the periphery's potentially huge contribution to global IR scholarship. However, the production and conveying of such knowledge and views nevertheless remain a problem.

13 Kimberly Hutchings, 'Dialogue Between Whom? The Role of the West/Non-West Distinction in Promoting Global Dialogue in IR', Millennium-Journal of International Studies, Vol. 39, No. 3 (2011), pp. 639-47; Karin M. Fierke and Vivenne Jabri, ‘Global Conversations: Relationality, Embodiment and Power in the Move towards a Global IR', Global Constitutionalism, Vol. 8, No. 3 (2019), pp. 506-35.

14 Amitav Acharya, 'Global International Relations (IR) and Regional Worlds: A New Agenda for International Studies', International Studies Quarterly, Vol. 58, No. 4 (2014), pp. 647-59.

15 Srini Sitaraman, 'Power and Knowledge: International Relations Scholarship in the Core and Periphery', Asian Journal of Peacebuilding, Vol. 4, No. 2 (2016), pp. 241-70; Yong-Soo Eun, 'Opening up the Debate Over “Non-Western" International Relations', Politics, Vol. 39, No. 1 (2019), p. 5; Amitav Acharya and Barry Buzan, The Making of Global International Relations: Origins and Evolution of IR at its Centenary (Cambridge: Cambridge University Press, 2019).

16 Qin Yaqing, 'A Relational Theory of World Politics', International Studies Review, Vol. 18, No. 1 (2016), pp. 33-47. 
This study proposes, therefore, that the missing link in the core-periphery dialogue, and thus a potential answer to the question of a core-periphery scholarship imbalance, may lie in the ways in which research on the periphery is being conducted, i.e. methodology. Methodology-and agreed upon understandings of quality in methodological practice-can help us to explain the origins of the conveyance problem with regard to core-periphery dialogue, and also serve as a tool to tackle it. As the IR discipline is abandoning paradigmatic research ${ }^{17}$ in favour of analytical eclecticism, ${ }^{18}$ it is incumbent upon IR students and scholars everywhere to pursue methodological competence. Focusing on the execution of quality research can also put aspiring scholars in a better position to make theoretical contributions in a scholarly context wherein hierarchies exist not just between the core and periphery, but between contending ontological and epistemological positions as well. ${ }^{19}$ Ultimately, absent a revolution focused on methodological quality, any proposals as regards theorising and goals which address the production problem by developing either local disciplinary communities or the broader IR discipline through direct promotion of theorising in the periphery may be untenable.

In making this proposal, the article also aims to push the now substantial literature on core-periphery disciplinary relations towards more practical suggestions for true IR globalisation. The 40 or more years of discussion that has accumulated on the topic of core dominance of the discipline continues largely to revolve around descriptions and critiques of the imbalance-along with discussions of what constitutes the core/periphery and varying interpretations of how the imbalance manifests. Yet the concrete questions remain: What exactly can be done to speed up a change in the imbalance? What kinds of institutional reorganisations should take place? What forms might a better core-periphery 'dialogue' take, and how can it be facilitated?

The call in this article for a refocusing in the periphery on quality methodology as a lingua franca for core-periphery dialogue is an effort to provide such a concrete suggestion. It is also an attempt at periphery self-reflection, rather than a continued focus on the crimes of the hegemonic core in this relationship. Although unsurprising and justified, core 'bashing' can only advance the issue up to a point. Ultimately, on a practical level, it is in the periphery that changes in core-periphery disciplinary relations are most urgently needed, so it makes sense to seek ways of initiating those changes from within it.

17 David R. Lake, 'Theory is Dead, Long Live Theory: The End of the Great Debates and the Rise of Eclecticism in International Relations', European Journal of International Relations, Vol. 19, No. 3 (2013), pp. 567-87.

18 Daniel Maliniak, Amy Oakes, Susan Peterson and Michael J. Tierney, 'International Relations in the US Academy', International Studies Quarterly, Vol. 55, No. 2 (2011), p. 439; Rudra Sil and Peter Katzenstein, 'Analytic Eclecticism in the Study of World Politics: Reconfiguring Problems and Mechanisms across Research Traditions', Perspectives on Politics, Vol. 8, No. 2 (2010), pp. 411-31; Colgan, 'Where is IR Going?', pp. 486-98.

19 Eun, 'Opening up the Debate Over “Non-Western' International Relations"', p. 11. 
In order to support this argument, the next section of the article discusses what is meant here by methodology and, more specifically, by 'quality' methodology. It then provides details on why focusing attention within the IR periphery on quality methodology could help to improve core-periphery imbalances in the discipline. The study then goes on to explore this proposal by closely examining the state of one local IR disciplinary community: Turkey's. In addition to assessing how methodology is viewed and addressed in Turkish IR, an evaluation is also made of the quality of methodological approaches employed by Turkish IR scholars.

\section{A Revolution in Methodological Quality}

Before talking about the intention behind this call for a revolution based on methodology, consider first the controversial accompanying term: quality. The consistent discrepancy between a growing quantity of periphery IR scholarship and its continuing absence of equivalent impact reveals a quantity-quality gap that suggests the need for local reflexivity. Although the volume of IR scholarship in the periphery is rapidly expanding, the standards of what constitutes 'good' scholarship often remain hazy and infrequently questioned. This is not to say that quality issues are more serious in the periphery than in the core, but it does require acknowledgement that quality issues may be a part of the core/periphery dialogue problem and the failure to recognise periphery scholarship.

Indeed, quality issues may be particularly important even in periphery countries that have begun imposing strict guidelines on what constitutes acceptable publications with regard to academic hiring and promotion, usually based on their being published in internationally recognised indexed journals. Such requirements, though understandable, inevitably put extra pressure on scholars who are often at a disadvantage linguistically, who have extremely heavy teaching loads, and who may have inadequate access to full-text publications. The natural response under such conditions may be to seek out easier routes, whether through choosing the research areas/topics that are most likely to get accepted abroad (e.g. assuming 'native informant' or 'quasi-official' roles), ${ }^{20}$ by adopting 'easier' methodologies (e.g. churning out the uninformed, non-theoretical, large-N studies), ${ }^{21}$ or through outright disingenuous practices (e.g. submitting to 'international' journals that take financial payments in return for less stringent reviewing procedures). ${ }^{22}$ The point is not to assign blame, but to address honestly the issue of quality of scholarship, and thereby offer suggestions that may contribute to its

20 Kristensen, 'How Can Emerging Powers Speak?', pp. 637-53.

21 Criticised by Benjamin J. Cohen in 'Are IPE Journals Becoming Boring?', International Studies Quarterly, Vol. 54, No. 3 (2010), pp. 887-91; John Mearsheimer and Stephen M. Walt, 'Leaving Theory Behind: Why Simplistic Hypothesis Testing is Bad for International Relations', European Journal of International Relations, Vol. 19, No. 3 (2013), pp. 427-57.

22 Amin Erfanmanesh and Razieh Pourhossein, 'Publishing in Predatory Open Access Journals: A Case of Iran', Publishing Research Quarterly, Vol. 33, No. 4 (2017), pp. 433-44. 
improvement, rather than simply add additional conditions and thus motivation for seeking ways around them.

To define what may constitute quality methodology, we also have to turn to the second part of the phrase: 'methodology'-a broader term than 'methods'. The latter refers to techniques and tools of data collection and/or analysis, whether quantitative or qualitative, e.g. interviews, document analysis, discourse analysis, archival work, focus groups, event data, various statistical tests, or process tracing. 'Methodology', on the other hand, as used in this article, encompasses all the steps of overall research design. Six general steps may be identified as involved in the process of research design or 'methodology': (i) asking a research question/positing an argument; (ii) displaying an understanding of relevant earlier scholarship/discussions and how the current research fits into it; (iii) determining an approach and/or methods appropriate for seeking answers to the research question/exploring the posited argument; (iv) presenting logical evidence to answer the research question/logically support the argument; (v) discussing how the findings/arguments contribute to the previous literature; and (vi) presenting policy and/or theoretical implications.

This broad concept of methodology also includes the 'why' behind a researcher's choice of methods. In other words, these methodological steps both reflect and determine the underlying rationale, objectives, and theoretical grounds behind the study, and thereby justify the methods used. Although arguments may be raised about the exact definition of what should be considered as relevant steps in the process of research methodology, two things should be indubitable. The first is the distinction between methods and methodology as defined above. The second, and perhaps even more important, is that the understanding here of 'methodology' as overall research design does not include any epistemological or ontological preferences or prejudices. It intends merely to encapsulate the idea of a well-constructed, adequately justified, clearly expressed, and subsequently applied research design, regardless of ideological starting point or end result. In other words, whether one begins a research inquiry seeking to understand a phenomenon or test a hypothesis, or whether one applies quantitative or qualitative instruments of data collection or analysis, is unimportant. What is important is that one meets accepted standards of methodological quality within that chosen approach and through the application of those chosen tools.

With this understanding in mind, how might 'quality methodology' serve as a possible bridge to effective core-periphery communication? If publications serve as the key venue for core-periphery communication, we might say that core publication outlets face a compatibility issue when they receive 'differently' produced or unfamiliarly structured works. This is not unlike what occurs in real-world IR; for instance, when it is said that North Atlantic Treaty Organization (NATO) military systems are incompatible with Russian military products. Even though they have the same purpose and are made up of the same material, a Russianproduced S-400 is 'incompatible' with NATO missile systems. In publishing, this compatibility issue may occur to such a degree that editors and referees struggle to grasp the material's content, and are thus quick to identify defects. 
Methodologies, which encompass a variety of tools and techniques (methods), and expertise in applying them in a competent and skilled manner, can be considered as constituting the universal language of an academic discipline, and thus a way of addressing these incompatibilities.

If the members of periphery IR communities cannot use that language effectively, the first casualty will be apparent in our struggle to develop serious disciplinary debates within our local disciplinary communities. Without those debates and the strong methodological approaches and methods that help support them, there will be no accumulation of scholarship and no deepening of knowledge, and hence no maturing of the local disciplinary community. Subsequently, as described above, without quality in methodology, we in the periphery cannot 'speak' with the core disciplinary community. This inability hurts not only periphery IR but the broader discipline as well, by limiting discussion. The social world has been described as comprising multiple voices, perspectives, and subjective worlds, with the transformation of people and communities taking place through dialogue among these multiple voices. ${ }^{23}$ The voice of periphery IR is thus important not just for its own sake, but because there is a need for both-allsides to engage in dialogue with each other to develop further everyone's understandings and perspectives. It is possible to argue that for all parties-core and periphery-methodology provides a means of communication, a set of 'signs' that are mutually intelligible and which, therefore, can allow for such dialogue.

It is worth spending a moment to discuss a bit further what is meant by a set of signs for communication, and how these signs can go beyond the understanding of different languages of communication ${ }^{24}$ to encompass other signs, in this case, the 'language' of methodology. If we look at scholarship in the Science, Technology, Engineering, and Mathematics (STEM) fields, we are more likely to find a common disciplinary language characterised by greater reliance on signs like set rhetorical patterns and structures, numerical formula and calculations, short texts buttressed by visuals and graphics, widely accepted patterns and practices of conducting research, and frequently used terminology. Indeed, researchers in linguistics have long noted disciplinary differences in academic writing patterns. ${ }^{25}$

23 Mikhail M. Bakhtin and Michael Holquist, The Dialogic Imagination: Four Essays (Austin: University of Texas Press, 1981).

24 For example, English, French, Chinese etc., as problematised in Anne-Marie D'Aoust, 'Accounting for the Politics of Language in the Sociology of IR', Journal of International Relations and Development, Vol. 15 (2012), pp. 120-31.

25 For example, Richard Holmes, 'Genre Analysis and the Social Sciences: An Investigation of the Structure of Research Article Discussion Sections in Three Disciplines', English for Specific Purposes, Vol. 16, No. 4 (1997), pp. 321-37; Ken Hyland, 'Disciplinary Differences: Language Variation in Academic Discourses', in Ken Hyland and Marina Bondi, eds., Academic Discourse Across Disciplines (Frankfurt: Peter Lang, 2006), pp. 17-45; Budsaba Kanoksilapatham, 'Rhetorical Structure of Biochemistry Research Articles', English for Specific Purposes, Vol. 24, No. 3 (2005), pp. 269-92; Hilkka Stotesbury, 'Evaluation in 
Hyland ${ }^{26}$ for example, compared academic writing in four disciplines (electrical engineering, biology, business, and applied linguistics), focusing specifically on set patterns of word groupings (lexical bundles) that occur repeatedly. $\mathrm{He}$ found clear differences between the two STEM fields and the two social science disciplines, with biologists using the smallest range of bundles overall, and engineers showing the greatest reliance on 'pre-fabricated structures'. The results led Hyland to conclude that in 'technical subjects [language is used] in routinely patterned, almost formulaic ways' ${ }^{27}$ Unlike the academic discourse of business or applied linguistics, this routine 'language' of the engineers and biologists was much more likely to be focused on the research objects or contexts, specifying aspects of models, equipment, materials, or features of the research procedures.

Similarly, Holmes ${ }^{28}$ compared research article structures across disciplines, and concluded that those in the 'hard sciences' featured far more predictability and more recycling of generic moves, resulting in more uniform discourse patterns than those in the social sciences. Mastering these much more limited and formulaic discourse patterns, many of which relate to methodology, and thus adhering to these norms of common 'language', may help periphery scholars in those 'hard science' fields to overcome any linguistic shortcomings. In other words, with a greater reliance on 'disciplinary language' expectations, the barriers relating to English proficiency in the natural sciences may be fewer than those facing scholars in the social sciences or humanities.

When it comes to publishing, few would deny that journal referees, upon encountering linguistic errors in a manuscript, are apt to become impatient and thus more aggressive in their criticisms. ${ }^{29}$ In the natural sciences, however, where core journals and referees may be more likely at least to find that overall methodological consistency (the disciplinary 'language' noted above) acts as the common language, they may be less likely to succumb so rapidly to linguistic impatience and instead give the ideas and findings a chance, so cognising that if the latter are valid, additional linguistic aides and editing support systems can be suggested and later applied. In this case, we see how methodologies may serve as common languages that help to break through the linguistic glass ceiling that so many periphery scholars face.

Obviously, finding such common disciplinary 'languages' may be more complicated in disciplines that employ not just widely diverse research approaches and

Research Article Abstracts in the Narrative and Hard Sciences', Journal of English for Academic Purposes, Vol. 2, No. 4 (2003), pp. 327-41.

26 Ken Hyland, 'As Can Be Seen: Lexical Bundles and Disciplinary Variation', English for Specific Purposes, Vol. 27, No. 1 (2008), pp. 4-21.

27 Ibid., p. 10

28 Holmes, 'Genre Analysis and the Social Sciences', pp. 321-37.

29 Some referees may subconsciously overemphasise linguistic errors in works out of the periphery. A well-published, native English speaker, affiliated with a Turkish university and writing on Turkish issues has shown me examples of blind reviewer comments he has received, such as 'surprisingly well-written' or 'should still be shown to a native speaker for editing', which clearly reveal linguistic preconceptions. 
methods but wherein researchers adopt strikingly different epistemological positions, but not impossible. Similarly, it does not entail imposing methodological limitations, but rather, defining methodological guidelines for each approach or toolin other words, clarifying various disciplinary 'languages'. It's worth considering, therefore, that greater methodological awareness, skilled training in, and use of methods may be the social sciences' best response to overcoming barriers that impede the incorporation of periphery scholarship into the core production line.

Unlike methodologies, theory, or the application of 'theoretical perspectives', may by its very nature be particularly ill-equipped to serve as the needed yardstick for distinguishing eligible scholarship and thus allowing a 'voice' from the periphery. James Rosenau ${ }^{30}$ once described theory as 'imagination', not in the sense of being fabricated or unreal, but in being the product of creative thinking. How can we rely, as a consistent measurement of quality, on something that is inherently the product of imagination? Ideally, a yardstick should be something with broadly accepted features or attributes that can be either quantitatively or qualitatively judged in a common manner. Interestingly, Rosenau's full statement was 'theory is imagination, method is art'. While creative imagination spawning theory is obviously critical to furthering knowledge, methodological art is equally important in providing a frame for that imagination.

Methodology training and development may serve as a starting point for assessing a disciplinary community and also be of further benefit, insofar as methods and methodology are less open to one group's having clear ownership of them. IR theory is generally recognised as being 'owned' by the core (in the sense that current dominant IR theories originate in the core), and thus periphery IR is generally forced to import, copy, or assimilate into those perspectives and approaches. However, methods and methodologies-in the research design sense described earlier-are arguably open to all. They are tools or steps, and whoever excels in their use can be judged by similar standards and apply them in new and unique ways appropriate to their contexts.

Some will argue that there still remains the risk of assimilation through methodological synchronisation, since methods, like theoretical concepts, have also been produced in the core. Indeed, methodology has not gone unscathed in discussions of core dominance. It has been nearly 20 years since Tuhiwai Smith's ${ }^{31}$ groundbreaking condemnation of the imperialist and colonialist side of research, and the subsequent call for indigenous methodologies that continues today ${ }^{32}$ or has taken on different forms, such as recommending 'glocal' methodologies. ${ }^{33}$

30 Personal communication, 2002.

31 Linda Tuhiwai Smith, Decolonizing Methodologies: Research and Indigenous Peoples (London and New York: Zed Books, 1999).

32 For example, Maggie Walter and Michele Suina, 'Indigenous Data, Indigenous Methodologies and Indigenous Data Sovereignty', International Journal of Social Research Methodology, Vol. 22, No. 3 (2019), pp. 233-43.

33 Giampietro Gobo, 'Glocalizing Methodology? The Encounter Between Local Methodologies', International Journal of Social Research Methodology, Vol. 14, No. 6 (2011), pp. 417-37. 
The risk of methodological colonisation in the IR discipline has also been pointed out. Arguments have been made about 'American' positivism and rationalism dominating the field of IR, so serving as an additional form of core oppression, ${ }^{34}$ and of periphery scholars becoming 'social science socialised'. ${ }^{35}$ Such views, however, seem to find their basis in broader criticisms of the current 'mathematisation' of the IR discipline, also described as the shift to 'hypothesis testing, ${ }^{36}$ which is ultimately seen as going hand-in-hand with a deprioritising of theoretical innovation. The problem with such criticisms within the field of IR, whether with regard to the discipline at large or as part of an argument about the domination of American positivism, is that they risk either conflating methods with methodology (methodology comprises far more than just large-N quantitative studies), or ontology/epistemology with methodology (methodology is relevant far beyond a positivist approach to research).

Some will disagree that methodology can be separated from ontology. They may argue that one's ways of knowing cannot be separated from ways of doing research, that is, from its overall design (here, methodology) and thus the tools (here, methods) used for conducting it. ${ }^{37}$ Such a perspective is reflected in those who argue that 'tools' or methods are not neutral. ${ }^{38}$ When thinking in particular about IR disciplinary development in the periphery, however, a more pragmatic interpretation of methodology's role may be necessary, building instead on Bennett, ${ }^{39}$ or Friedrichs and Kratochwil, ${ }^{40}$ to propose that 'methodology' be accepted as a broad term devoid of a particular epistemological or ontological agenda.

If we draw on, for example, Friedrichs and Kratochwil's understanding of a pragmatic approach, we can suppose a common methodological language that is based on principles of transparency (of positioning); reflective and evolving adaptation of a framework (or propositions or theory, depending on one's orientation); and application of that chosen approach. Such a methodological language

34 Darryl S. L. Jarvis, 'International Relations. An International Discipline?', in Darryl S. L. Jarvis and Robert M. Crawford, eds., International Relations-Still an American Social Science? Toward Diversity in International Thought (Albany: State University of New York Press, 2001), pp. 369-80.

35 Pinar Bilgin, 'Thinking Past “Western IR"?', Third World Quarterly, Vol. 29, No. 1 (2008), pp. $5-23$.

36 Mearsheimer and Walt, 'Leaving Theory Behind', pp. 427-57.

37 For example, Patrick T. Jackson, 'Must International Studies be a Science?', Millennium: Journal of International Studies, Vol. 43, No. 3 (2015), pp. 942-65.

38 Claudia Aradau and Jef Husymans, 'Critical Methods in International Relations: The Politics of Techniques, Devices and Acts', European Journal of International Relations, Vol. 20, No. 3 (2014), pp. 596-619.

39 Andrew Bennett, 'The Mother of All Isms: Causal Mechanisms and Structured Pluralism in International Relations Theory', European Journal of International Relations, Vol. 19, No. 3 (2013), pp. 459-81.

40 Friedrichs and Kratochwil, 'On Acting and Knowing', pp. 701-31. 
can apply to anyone, whether coming from a so-called 'qualitative' or 'quantitative' background, or from a positivist or post-positivist perspective.

Decrying an overemphasis on 'methodology' because it assumes a positivist, rationalist approach to inquiry and research is reading too much into the term. We do not have to look far to find examples of works clearly emphasising that methods can be very much a part of a critical project. ${ }^{41}$ And while remaining conscious of different perspectives, common ground may be found on exploring methodological issues related to quality, such as the ever-present need for transparency. ${ }^{42}$ Moreover, a call for an even greater emphasis on methodology should not be interpreted as denying the importance of theory. Rather, it is an effort to recognise that good quality methodology — of all epistemological perspectives-is the necessary basis for effective and meaningful theorising. ${ }^{43}$

The inherent differences between methods and theories is perhaps even more important in explaining why methodological assimilation does not pose the same kind of risk as does theoretical assimilation. Theories are perspectives, whereas methods-or even the broad steps of methodology-are tools for production and creation. Therefore, learning about and assuming a theoretical perspective involves the passive-regardless of how informed it may be-acceptance of a previously established view. Learning a method or methodological approach, on the other hand, means acquiring a tool that enables one to discover or create new things.

To give an everyday life analogy, imagine a friend asking for help in making an important decision. You may provide her with a methodological tool, for example, writing a pros/cons list that helps her see the relative benefits and disadvantages of her possible options, and thereby gain new insights into what might be the best choice. On the other hand, just telling her your own perspective (theory) on the problem, however insightful it may be, will not actually help her to become more creative in seeking her own solutions to this or future issues. Similarly, learning about and adopting theories from the core does not help periphery IR scholars become more creative, nor does it necessarily facilitate their understanding of how they might view the world or global problems/issues differently. Using the West's methods, on the other hand, might do just that.

41 For example, Amber J. Fletcher, 'Applying Critical Realism in Qualitative Research: Methodology Meets Method', International Journal of Social Research Methodology, Vol. 20, No. 2 (2017), pp. 181-94; Jack Katz, 'A Theory of Qualitative Methodology: The Social System of Analytic Fieldwork', Method(e)s: African Review of Social Sciences Methodology, Vol. 1, No. 1/2 (2015), pp. 131-46; Daniela Lai and Roberto Roccu, 'Case Study Research and Critical IR: The Case for the Extended Case Methodology', International Relations, Vol. 33, No. 1 (2019), pp. 67-87.

42 Cora Lacatus, Daniel Schade and Yao Yuan, 'Quo Vadis IR: Method, Methodology and Innovation', Millenium Journal of International Studies, Vol. 43, No. 3 (2015), pp. 767-78.

43 See, for example, Alexander L. George and Andrew Bennett, Case Studies and Theory Development in the Social Sciences (Cambridge: MIT Press, 2004). 
To reiterate, this article is an effort to step back from the long-standing argument that periphery IR's failure to gain significant stature in IR scholarship has been essentially the fault of the core's 'not listening'. While this, too, has been true, it is time for a self-reflective accounting of what might unfairly be deemed as intellectual poverty in periphery IR. This article seeks to understand the dilemma that leads periphery scholars, despite having arguably deeper experience as regards IR activities and history, and their obvious imaginative potential, nevertheless still to fail in producing scholarship of global disciplinary resonance. The paper proposes that the answer may lie in the periphery's shortcomings in the art of methodology. The next section uses an example of one local IR disciplinary community in the periphery to explore further the damaging role that an underemphasis on methodology may inflict on disciplinary development and thus on core recognition of scholarship from that local community.

\section{IR in Turkey: A Case Study in Disciplinary Disappointment}

The sections below explore the case of the Turkish IR disciplinary community, with the overall aim of assessing how much importance those within the community place on methodology, and the quality of the methodological approaches applied in Turkish IR scholarship. The discussion begins with an overview of Turkish IR's relationship with methodology—how it is viewed and to what extent it is prioritised in the training of young IR scholars in Turkey. This relationship is explored both through the comments of Turkish IR scholars and by looking at university curricula and local publications in the field. The case study then attempts to assess the quality of methodology understandings and implementation in Turkish IR. It does this primarily through an examination of the methodology sections of IR dissertations produced in Turkey between 2014 and 2017, while also drawing on the experiences of the editorial team of one IR journal based in Turkey.

Friedrichs and Kratochwil's specifically pragmatic approach to research calls for sampling that finds a 'most important or most typical' case. ${ }^{44}$ For the IR discipline in the periphery, determining what is a 'most important' or 'most typical' case is a challenge, when debates are ongoing even as to what constitutes 'the periphery' itself. ${ }^{45}$ All will agree, however, that the 'periphery' is diverse, ranging from a broad understanding of its being the 'non-West', ${ }^{46}$ to one that includes all countries outside of the 'Anglosphere', including Western Europe, as semi-

44 Friedrichs and Kratochwil, 'On Acting and Knowing', p. 715.

45 For an interesting recent discussion on determining core/periphery boundaries from the 'other' side, see Helen L. Turton, 'Locating a Multifaceted and Stratified Disciplinary “Core"', All Azimuth, forthcoming.

46 Ersel Aydinli and Julie Mathews, 'Are the Core and the Periphery Irreconcilable? The Curious World of Publishing in Contemporary International Relations', International Studies Perspectives, Vol. 1, No. 3 (2009), p. 291. 
peripheral, ${ }^{47}$ to the perception that everywhere outside of the United States is, in a sense, the IR periphery. ${ }^{48}$ The Turkish IR community is both important and typical, therefore, as it intrinsically represents a parallel diversity. Taking into consideration institutional practices, infrastructure, and support systems, as well as faculty qualifications and educational culture, it is possible to identify Turkish universities that are on a par with the 'core of the core' in the IR discipline, those resembling the 'periphery of the periphery', and a range of others in between. Therefore, although it may be difficult for the experience of a single country to reflect the academic situation throughout the so-called periphery, the Turkish case may serve as a good sample, because a study which through the Turkish case captures a full picture of this internal diversity is best poised also to capture elements of relevance throughout the widely diverse global 'periphery' as a whole.

\section{Methodology and the Turkish IR Community: An Overview}

The IR discipline in Turkey, as measured by numbers of IR departments, students, and faculty, has grown rapidly in recent decades. From essentially revolving for many years around a single department at Ankara University, expansions to the numbers of universities around the country that began in the 1980s resulted in a total of 42 IR departments in 2008, which by 2012 had more than doubled to 109 , and by the year 2019 grown to 147. Numbers of faculty and students have also exploded in the past quarter-century, from approximately 5000 IR students in 1994 to nearly 190000 in 2019, and from just 81 faculty members in 1994 to almost 1500 in 2019 (see Table 1).

Numbers of publications have also increased over the same period, though arguably few major, globally acknowledged scholarly contributions have yet to come out of the Turkish IR disciplinary community. The long-held perception was that the absence of major scholarly accomplishments in Turkish IR stemmed from the failure of local scholars to engage in conceptual and theoretical work. One study on the IR discipline in Turkey revealed a 'theory fetishism', beginning in the 1990s, reflected among the then emerging scholars who spoke passionately about their IR theory knowledge and thus their superiority over the 'old school' IR scholars of the 1960s, 1970s, and 1980s, whose works they dismissed as focusing only on 'Turkish foreign policy issues, or some other empirical, national issues ... case studies. They were all historical issues. ${ }^{49}$ This new generation dismissed the older one's scholarship due to the latter's failure to cite popular core theories

47 For example, Jörg Friedrichs and Ole Wæver, 'Western Europe: Structure and Strategy at the National and Regional Levels', in Arlene Tickner and Ole Wæver, eds., IR Scholarship Around the World: Worlding Beyond the West (Oxon: Routledge, 2009), pp. 261-86.

48 For example, Klaus Gerd Giesen, 'France and Other French-Speaking Countries 1945-1994', in Knud Erik Jørgensen and Tonny Brems Knudsen, eds., International Relations in Europe: Traditions, Perspectives and Destinations (0xon: Routledge, 2006), pp. 72-99.

49 Julie Mathews, Mediating Academic Literacy Practices in a Second Language: Portraits of Turkish Scholars of International Relations, Ph.D. dissertation, McGill University, 2004, p. 173. 
Table 1. Numbers of Students and Faculty Members in Turkish IR Departments

\begin{tabular}{lccc}
\hline Level & $\begin{array}{c}\text { 1994-1995 } \\
\text { academic year }\end{array}$ & $\begin{array}{l}\text { 2010-2011 } \\
\text { academic year }\end{array}$ & $\begin{array}{c}\text { 2019-2020 } \\
\text { academic year }\end{array}$ \\
\hline Undergraduate students & 4575 & 23451 & 181193 \\
Graduate students & 722 & 2883 & 8952 \\
Faculty members (all ranks) & 81 & 612 & 1497 \\
\hline
\end{tabular}

and theoreticians. Signs of a new emphasis on 'theory' could also be seen with the founding of what is now one of the leading Turkish IR journals, Uluslararasi Iliskiler [International Relations], launched in 2004 with the specific aim of highlighting theoretical works.

Essentially, starting in the late 1990s, the understanding was that if Turkish IR scholars were only to move on to a more 'theory-based' approach to their research, then the scholarly products of that research would gain a wider audience, and Turkish IR would begin to play an active role in core IR debates and discussions. The result of this perceived shortcoming has been a drive among Turkish IR scholars, at least in rhetoric, to be 'more theoretical', and the emergence of a generation of IR scholars whose first response when asked about their research is to claim that they are 'doing theory'. According to one survey, a full $89 \%$ of Turkish IR scholars reported using a 'theoretical approach' to their research-significantly higher than the world average of $78 \% .^{50}$ The same TRIP survey found that when asked 'What is your main research area?', not a single Turkish scholar selected the 'research methods' option.

Whether as a side effect of the emphasis on theory in Turkish IR or for other reasons, issues related to methods, methodology, or basic research design, have arguably been neglected in the local disciplinary community. One indication of such neglect can be observed in the instructional practices in IR departments at Turkish universities. In 2018, there were 37 IR departments in Turkey offering undergraduate and graduate degrees at all levels $(\mathrm{BA}, \mathrm{MA}, \mathrm{PhD})$, and thus constituting, arguably, the most established IR departments among the more than 140 that existed at the time. Of these 37 IR departments, 5 can be commended for offering a variety (three or more) of graduate level courses related to different aspects of methodology, for example, courses highlighting specific data collection methods or exploring methodology from different broad paradigmatic perspectives (e.g. 'Qualitative Research Methods'). Several schools-four at the undergraduate level and nine at the graduate level-offered just two methodology-related courses. The vast majority, however, 31 at the undergraduate level

50 Mustafa Aydin and Korhan Yazgan, 'Turkiye'de Uluslararası lliskiler Akademisyenleri Egitim, Arastırma ve Uluslararası Politika Anketi' ('A Survey of the Education, Research and International Politics of International Relations Scholars in Turkey'), Ulus/ararası Iliskiler (International Relations), Vol. 9, No. 36 (2013), pp. 3-44. 
Table 2. Methods Courses in Leading Turkish IR Programmes

\begin{tabular}{lllllr}
\hline Level & $\begin{array}{l}\text { No methods } \\
\text { courses }\end{array}$ & $\begin{array}{l}1 \text { method } \\
\text { course }\end{array}$ & $\begin{array}{l}2 \text { methods } \\
\text { courses }\end{array}$ & $\begin{array}{l}3 \text { or more methods } \\
\text { courses }\end{array}$ & Total \\
\hline $\begin{array}{l}\text { Undergraduate } \\
\text { Graduate }\end{array}$ & $4(10.8 \%)$ & $27(72.9 \%)$ & $4(10.8 \%)$ & $2(5.4 \%)$ & 37 \\
\hline
\end{tabular}

and 23 at the graduate level, offered either just one course or no courses at all on methodology (see Table 2).

These numbers show that the most common practice in the curricula of these established IR departments in Turkish universities is to offer just one methodology course at the undergraduate level and one at the graduate level. Moreover, according to the course listings for these departments, these methodology classes are generally relegated to 'staff' teaching rather than being taught by an identified faculty member. While a single, well-taught methodology course could, in principle, be sufficient to provide students with a broad overview of different methodological approaches and tools, the lack of additional, specialised courses means that most Turkish IR students are not being allowed the opportunity for deep inquiry into the principles of research design, let alone given the chance to develop real expertise on a variety of approaches or techniques.

Perhaps even more difficult to accept is the handful of schools that manage to graduate MA and PhD students in IR without offering a single course in methodology or research design. Given that these tend to be schools offering instruction in Turkish rather than in English, one possible explanation beyond simply the lack of emphasis placed on methodology in the local discipline could be that of the limited number of locally published Turkish textbooks on research methodology in IR. As of this writing, there is only one original textbook published in Turkish specifically on the topic of research methodology in the IR discipline. The book in question, ${ }^{51}$ however, was intended for use in one specific online course in the 'open education' department of a single university, and is not used at other institutions. Moreover, there are no translations into Turkish of IR methodology books published in other languages.

The neglecting of methodological issues in Turkish IR extends beyond pedagogy to the realm of scholarship. Although there are dozens of locally published journals at least somewhat related to the field of IR, none emphasises methodological issues in their mission statements. That there are no Turkish IR journals explicitly focusing on methodology may not be terribly surprising, but what can be considered unusual is the lack of discussion about methodology, methodological quality, or research design. An examination of the leading (internationally indexed) Turkish IR journals over the five-year period from 2013 to 2018 shows

51 Ali Çarkoğlu, ed., Uluslararası iliş̧kilerde Araştırma Yöntemleri (Research Methods of International Relations) (Eskisehir: Anadolu University, 2013). 
that not a single article was published during these years that raised questions about or discussed issues related to methodology.

A final perspective on how methodology has been viewed in the IR disciplinary community in Turkey can be gained by directly asking the opinions of members of that community. The first-and so far only-workshop in Turkey focusing on methodology in IR was held in $2018,{ }^{52}$ its broad aim to bring local IR scholars together to discuss issues related to this topic with an intended concrete outcome of creating a methodology textbook in Turkish. ${ }^{53}$ The participants represented widely diverse backgrounds and areas of methodological expertise, both in terms of epistemological and ontological perspectives, as well as in technical methods and data collection techniques. Despite this diversity, as the final roundtable discussion revealed, common points were frequently apparent. These shared perspectives were broadly divided between generally negative judgements about the overall state of methodology in Turkish IR and specific criticisms about methodology education in Turkish IR departments.

At the most general level, when commenting on the state in Turkey of methodology in IR, there was broad agreement that although methodology is indeed

52 Details on the aims and scope of the workshop as well as the participants and resulting papers can be found on the website of the organizing Center for Foreign Policy and Peace Research, http://www.foreignpolicyandpeace.org/index.php/en/homepage/.

53 The pieces are also available in All Azimuth. For a discussion of various methodological approaches and methods from the perspective of Turkish scholars, see Ersel Aydinli, 'Methodological Poverty and Disciplinary Underdevelopment in IR', All Azimuth, Vol. 8, No. 2 (2019), pp. 109-15; Şener Aktürk, 'Temporal Horizons in the Study of Turkish Politics: Prevalence of Non-Causal Description and Seemingly Global Warming Type of Causality', All Azimuth, Vol. 8, No. 2 (2019), pp. 117-33; Belgin San-Akca, 'Large-N Analysis in the Study of Conflict', All Azimuth, Vol. 8, No. 2 (2019), pp. 135-56; Emre Hatipoğlu, İnanç Arın, and Yücel Saygın, 'Automated Text Analysis and International Relations: The Introduction and Application of a Novel Technique for Twitter', All Azimuth, Vol. 8, No. 2 (2019), pp. 183-204; Özgür Özdamar, 'An Application of Expected Utility Modeling and Game Theory in IR: Assessment of International Bargaining on Iran's Nuclear Program', All Azimuth, Vol. 8, No. 2 (2019), pp. 205-30; Ali Fisunoğlu, 'System Dynamics Modeling in International Relations', All Azimuth, Vol. 8, No. 2 (2019), pp. 231-53; Ismail Erkam Sula, 'An Eclectic Methodological Approach in Analyzing Foreign Policy: Turkey's Foreign Policy Roles and Events Dataset (TFPRED)', All Azimuth, Vol. 8, No. 2 (2019), pp. 255-83; Senem Aydın-Düzgit and Bahar Rumelili, 'Discourse Analysis: Strengths and Shortcomings', All Azimuth, Vol. 8, No. 2 (2019), pp. 285-305; Mustafa S. Palabıyık, "Broadening the Horizons of the "International" by Historicizing it: Comparative Historical Analysis', All Azimuth, Vol. 8, No. 2 (2019), pp. 307-25; Egemen Bezci, 'Secrecy and the Study of International History: Missing Dimension in Turkish Foreign Policy', All Azimuth, Vol. 8, No. 2 (2019), pp. 327-38; Alper Kaliber, 'Reflecting on the Reflectivist Approach to Qualitative Interviewing', All Azimuth, Vol. 8, No. 2 (2019), pp. 339-57; Konstantinos Travlos, 'Mobilization Follies in International Relations: A Multimethod Exploration of Why Some Decision Makers Fail to Avoid War When Public Mobilization as a Bargaining Tool Fails', All Azimuth, Vol. 8, No. 2 (2019), pp. 359-85. 
critically important to advancement of the local disciplinary community, it is often either neglected or full of misperceptions. Methodology's importance was emphasised as being, among other things, a route to 'legitimacy' that could ease Turkish IR's integration into the global IR community:

All research is based on justification. You need to justify why you are choosing a certain case, why are you dealing with a given phenomenon or given puzzles and so on. Methodology helps you to justify your research and give it more legitimacy in an international working atmosphere with colleagues from other countries.

All participants, however, expressed concerns over the current state of methodology in Turkish IR. Some of these assessments were broadly critical:

People here tend to use this assertion 'Oh, I predicted this long before these people published it.' OK fine, where did you publish your ideas? 'Well, I predicted this but they rejected my paper.' Why did they reject your paper? The 100 per cent truth is that they actually have no methodology; nothing replicable or reproducible of any kind to back their arguments ... they don't use any kind of measurement or device that allows you to demonstrate something that fits into a certain pattern. That just does not exist.

We have very basic methodology problems. Most of us don't even start with a genuine inquiry. Most of us start with an opinion. Then we define that opinion as a 'theory', but without methodology, theory becomes ideology. The majority of Turkish IR is handicapped by this reality.

Others offered more specific comments about common methodological misperceptions in Turkey. These criticisms stemmed from different points along the methodological spectrum:

If they see a number, they think that it's quantitative.

Many researchers in Turkey suffer from the misperception that if you act like a journalist and if you write the history of something, you are doing qualitative method research. They think that whatever they're not doing quantitatively goes into the basket of qualitative methods ...

In Turkey, those students who claim that they are using quantitative methods often lack a clear plan. They just start with numbers. 'I collected this data on HDP's vote share in eastSoutheastern Anatolia.' But why? Why are you collecting that data? What is your objective? What are you trying to show? We all have to start with an idea and a question-the basics of research design.

Many also shared criticisms about the ways in which methodology in IR is taught at Turkish universities. Reflecting on the findings above on the curricula of Turkish IR departments, several noted the students' lack of exposure to even the most basic concepts, and suggested that training starts too late:

I am teaching a quantitative methods course in a PhD program. My students don't even know what a dependent or independent variable is! We have to start giving the basic methods at the undergraduate level.

When you take the late start to research training in universities, and combine it with the complete lack of any exposure whatsoever to research design or even argument preparation during the high school years, then basically you've got a recipe for disaster. 
Some were concerned about the risk of reducing methodology classes to solely philosophical discussions while, conversely, others felt too much emphasis was given to techniques and not enough to more abstract issues:

\begin{abstract}
When we think about research problems, I ask my students to give me some examples of political phenomena that interest them. They say, for example, the Syria-Turkey water conflict or Iran's nuclear weapons programme. Then I ask them, these examples are great but what is this a case of? What is the broader issue that you are trying to conduct your research on? They don't know how to do this. The big challenge we have is the ability to reach abstraction from concrete phenomena.
\end{abstract}

All agreed, though, that whether in pedagogical discussions or scholarly ones, methodological issues should avoid new kinds of prioritising. Methodology or methods should not be given priority over theory-the two need to work in tandem-and nor should there be any preferring one type of methodological approach over another. This common spirit was perhaps best summed up in the words of one participant who had this methodological recommendation for IR students:

Be promiscuous and try everything! Try even the kinds of methods that you don't particularly like. Maybe you come from a qualitative background and you hate numbers. It doesn't matter. Go and learn regression, learn formal modelling. Learn mathematical modelling. There should be this brief period of time when all PhD students should be completely dazzled with methodology. That is not a bad thing, but it's not what we see happening now in Turkey.

The above figures and quotes provide a picture of a disciplinary community that has to a large extent ignored issues of methodology and basic research design both in its scholarly discussions and in its training of future practitioners and scholars of IR. The question that remains is whether or not this neglect has had impact on the resulting methodological quality of works written by locally trained Turkish IR scholars.

\title{
Quality in Turkish IR Methodology
}

Attempting to evaluate the overall quality of the methodological approaches and tools used in Turkish IR scholarship is a challenging task, both because it might appear to give preference to certain types of methodology over others, and also because published—and therefore easily accessible-works are presumably the most successful, so may not represent an accurate picture of the broader state of disciplinary scholarship. To try to avoid these risks, the following section explores the 'quality' issue in two ways: first, with an inside look at the submission and desk rejection records of an IR journal based in Turkey; and second, by broadly analysing the treatment of methodology in student $\mathrm{PhD}$ dissertations from Turkish IR departments.

All Azimuth is a relatively young IR journal based in Turkey but whose mission is to serve as a voice for IR scholars from around the world, in particular those in the periphery. Because of this emphasis, the journal has an overt policy of providing extensive feedback to all submitting authors, and for those submissions that present particularly intriguing or novel ideas but suffer from 
methodological or language problems (the journal is published in English), the editorial team works hand-in-hand with the authors to bring the pieces to a publishable level. Now in its eighth year of publication, All Azimuth has an active international editorial team, and is established as a part of the Emerging Social Science Citation Index list. Over the last two years, the journal has received on average about 65 article submissions annually, approximately $50 \%$ of which have ultimately been rejected.

When looking specifically at the numbers of submissions coming from Turkish scholars over the past two years, the ratio of rejections is quite similar. In 2018 there were 29 submissions with 13 rejections, and in 2019 there were 31 submissions with fourteen rejections. To better understand these numbers, interviews were conducted with members of the editorial team about their experiences when assessing these submissions and determining whether they should be sent out for blind review.

An initial assumption, that language issues were probably a problem, was largely dismissed with references to their in-house language editor, whose job iis

'basically to turn us all into native-English speaking writers'. Instead, without exception, according to the journal editors, the largest problem they see is shortcomings in overall research design and methodology:

It happens all the time that we get pieces with impressive titles, important subjects, and a great opening sentence making a big claim, but then pages and pages pass, and you're still left trying to figure out the structure of the paper.

\begin{abstract}
So many times I look at the submissions and I simply don't know what the argument is! I sometimes spend a day on a paper and can't find a clear line of argumentation. When you look at our desk rejection rate it's pretty high. We really hate the idea of desk rejection but at the end of the day, many times we can't justify taking up the referees' time on pieces that don't even have a clear argument or basic research design.

When we see something really interesting, we'll prepare a detailed report for the author requesting revisions before we can send it out for review. We'll say, look, this is your actual research question, here is how you can argue it, and here's a way you can look for evidence for it. Sometimes, they turn around and really do wonders with this feedback. They simply don't know how to design a study. In an ideal world, I think I could have been the co-author on some of these pieces!
\end{abstract}

While the editors agree that these observations are not exclusively applicable to the submissions they receive from Turkish scholars, Turkish works are often within this group. These editors' comments seem to represent the full circle of the evidence presented above. Methodology is generally given minimal emphasis in both undergraduate- and graduate-level training in IR, and there are inadequate resources for such training. At the scholarship level, the focus in local academic venues lies outside of methodology or issues related to methodological development. Unsurprisingly, then, the experience, at least of this IR journal, is that the resulting scholarship produced by those who have come up through this system often shows a lack of good methodological planning and application. 
Although the All Azimuth editors' experiences provide some suggestions about the quality of methodology in Turkish IR, perhaps the best assessment mode is that of looking at $\mathrm{PhD}$ dissertations by emerging Turkish IR scholars. Dissertations provide particularly valuable insights into this question, because as a genre they explicitly demand some engagement with methodological questions and, as successful-but unpublished-works, they represent most clearly the standards of the local disciplinary community, and not of a potentially more diverse audience of journal reviewers.

Two hundred and seventy-three $\mathrm{PhD}$ dissertations were completed in IR departments in Turkey in the five years between 2012 and 2017. After successful defences, all theses and dissertations are submitted to the centralised Higher Education Council for archiving, and made available online for public access. ${ }^{54}$ All 273 IR PhD dissertations between 2012 and 2017 were analysed for their methodological content. To avoid the complications of trying to find an agreedupon method of assessing the quality of approaches or data collection/analysis techniques used in these methodologically diverse works, a simple framework of analysis was applied: Did the dissertation have any clear reference to methodology or research design? If so, to what extent was that methodology discussed? The works were then divided into four possible categories: (i) those with a full, separately labelled chapter focusing on methodology and research design; (ii) those with at least one clearly identified subsection on methodology in a chapter under another title, e.g. Introduction, Theoretical Framework; (iii) those that mention methods or methodological issues or research design at some point but not in a separately labelled subsection; and (iv) those without any mention of methodology at all.

The resulting numbers (see Table 3) provide a picture that is in line with the overall negligence of methodology in Turkish IR pedagogy and scholarly discussion. Only thirty of the $273 \mathrm{PhD}$ dissertations $(10 \%)$ had a separate chapter exclusively focusing on the methodology of the study. Another $82(30 \%)$ had a labelled methodology subsection in one of the dissertation's chapters, and 102 $(37 \%)$ made some mention of methodology, research design, or methodsthough not a separate, labelled subsection-most commonly located in the introduction of the dissertation. A shocking 59 of these works $(21.5 \%)$ made no mention at all of methodology used.

The numbers were more disturbing still when dissertations were divided according to language. Many of the leading IR programmes in Turkey are conducted in English, at schools which rank as the most prestigious in the countryboth according to local evaluations (English-medium programmes are those requiring the highest university placement test scores to enter) and international scores like the Times Higher Education World University Rankings. The results for dissertations written in English were slightly better, with approximately $60 \%$ having either a separate methodology chapter or a separately labelled subsection on methodology. However, when looking at the $175 \mathrm{IR} \mathrm{PhD} \mathrm{dissertations}$ 
Table 3. Methods in Turkish IR Dissertations

\begin{tabular}{lccccr}
\hline Language & $\begin{array}{l}\text { Separate methodology } \\
\text { chapter }\end{array}$ & $\begin{array}{l}\text { Labelled methodology } \\
\text { subheading }\end{array}$ & $\begin{array}{l}\text { Some explanation } \\
\text { of methodology }\end{array}$ & $\begin{array}{l}\text { No mention of } \\
\text { methodology }\end{array}$ & Total \\
\hline Turkish & $15(8.6 \%)$ & $38(21.7 \%)$ & $80(45.7 \%)$ & $42(24 \%)$ & 175 \\
English & $15(15.3 \%)$ & $44(44.9 \%)$ & $22(22.4 \%)$ & $17(17.3 \%)$ & 98 \\
\hline
\end{tabular}

completed in Turkish between 2012 and 2017, nearly a quarter (24\%) made no mention at all of methodology, and the majority $(67.4 \%)$ discussed methodology either in a subsection or simply in passing. Fewer than $10 \%$ had a full separate chapter devoted to methodology.

Needless to say, these numbers do not even begin to consider the diversity of breadth or clarity of definition of the methodologies cited as having been used in these studies, let alone allowing for assessment of the consistency and efficacy with which any of the cited methodological tools and approaches were actually applied. As lamented by several of the participants in the earlier mentioned workshop, the 'good' universities tend to ensure some inclusion of methodology in their students' theses and dissertations, but that does not ensure follow-through. In the words of one scholar: 'Even in good programmes ... the methodology section may be little more than a formality. Has the candidate actually applied what they said they would? That's the real problem.'

One is left to conclude that there is indeed a methodological quality problem in Turkish IR. Its sources can be ascribed to culture-first in the sense of educational culture, and subsequently of disciplinary culture. As regards educational culture, certain characteristics of the traditional Turkish education system naturally work against the production of good quality research design and methodology. With a huge youth population, limited resources, and therefore large class sizes and inadequate teacher training, Turkey relies on an education system that is capable of efficiently measuring and ranking students. The resultant system is one based on memorisation and multiple-choice testing, and which hence fails to promote analytical thinking, reflection, or application. Alternative systems, such as the International Baccalaureate, are applied in a few schools in Turkey, and aim to instil, even in primary school-age students, an appreciation of the research design process. The superior analytical capacity of students coming through such programmes, compared with those from the traditional system, is frequently noted by faculty in the Turkish higher education system. Unfortunately, only a tiny fraction of Turkish students do come through such programmes; the vast majority remain limited by the restrictions of the traditional education system.

Turning to disciplinary culture, as discussed earlier, Turkish IR has suffered from a form of 'theory-fetishism' in recent decades that has pushed methodology on to the back burner. The subsequent deemphasising of methodology in IR training and scholarly discussions can be seen as a natural source of today's lower quality methodology production. Moreover, as is perhaps typical in an IR 
disciplinary community located in a developing country, IR in Turkey is very much driven by policy discussions, which generally demand quick opinions and commentaries, rather than methodical, scholarly works based on rigorous research designs. For newcomers to the discipline, the most well-known and seemingly influential IR scholars are likely to be those emanating from this policy world. Therefore, investing in the methodological development needed for a more academic, scholarly career may not seem to be the most attractive route for professional development. These disciplinary realities have also contributed heavily to the current poor state of methodological quality in Turkish IR.

\section{Recommendations}

The above look at the Turkish IR disciplinary community revealed that methodology generally remains underemphasised, both pedagogically and in scholarly discussions and practice. The evidence further suggests that the implications of this inadequate training can be observed in the academic outputs of the community's members. What, in light of the above, can be done in specific, practical terms? A few concrete suggestions can be made, first at the instructional level and then at that of academic scholarship.

The first step towards achieving 'quality methodology' in Turkish IR is to improve methodology training in university IR departments. Improving quality in broader methodology or research design requires training IR students in the basic aspects of research design-how to come up with and ask a genuine research question; how to gain and demonstrate familiarity with the relevant literature; how to establish a connection between the research question(s) and the literature; how to determine appropriate methodology(ies) for responding to the research question; and so on. Early engagement with research and methodology could be encouraged by requiring even undergraduate students first to assist with faculty research projects and then to conduct small-scale research studies themselves in the form of senior/capstone projects.

Moving on to the level of basic methods, undergraduate IR students must be introduced to a wide range of data collection and analysis techniques. While a general 'research methods' course may be sufficient at the undergraduate level as a bare minimum, at the graduate level additional elective courses and/or workshops in specific techniques and tools should be made regularly available. Students should be required to learn about a variety of methods and taught to view them as tools for exploration from among which they can later select according to the type of research they end up carrying out. Training courses both for students and for faculty members who wish to expand or update their methodology skills, therefore, should be readily available. Rather than relying idealistically on intrinsic motivation to promote involvement in methods-based professional development, universities could recognise and reward such efforts as part of annual faculty evaluations.

In addition to building up students' and scholars' skills in different techniques and tools, awareness on the benefits of adapting or innovating new techniques for 
emerging problems in the field, e.g. documentary filmmaking, ${ }^{55}$ or computational IR, ${ }^{56}$ should also be heightened. This could also include promoting openness to the building of hybrid techniques and approaches, from multi-method research agendas ${ }^{57}$ to drawing on approaches and techniques from other disciplines. To achieve this, universities could openly recommend joint research efforts, including interdisciplinary projects and publications.

At the broader level, in periphery disciplinary communities like that in Turkey, where theory or theorising has been emphasised, the response should not be to scrap theory appreciation. Rather, there should be a shift towards recognising the importance of theory in a balanced way that avoids theory-fixation at the expense of methodology. An unfortunate side effect of theory adulation, as seen in Turkish IR, is that the educational culture in many graduate IR programmes encourages graduate students to choose thesis supervisors on the basis of their 'theory identities', for example, as a 'critical' scholar or a 'Realist'. The result is that the ensuing professor/graduate student relationship becomes one largely of ideology transfer rather than of well-rounded training in ways of exploring issues, asking questions, and seeking responses.

In many cases the nature of 'knowledge' transition involves adaptation of a particular body of literature and of predetermined positions. Obviously, such unquestioned transfer is unconducive to critical self-reflection or to the generating of debates. In fact, without the ability to engage critically with the extant literature and formulate questions it may not be possible to transcend disciplinary and global hierarchies. ${ }^{58}$ The entire graduate-student mentoring practice can thus easily turn into a process of self-confirmation rather than of questioning, exploring, and/or testing in the light of new evidence, input, and data-things which good quality methodology and methods, on the other hand, can help facilitate. Another first step in shifting Turkish IR disciplinary thinking about methodology, therefore, could be for IR departments to use their faculty members' varying interests in methods and methodology as selling points, and to emphasise those explicitly, in addition to topic or area interests, for purposes of graduate student recruitment.

55 William A. Callahan, 'The Visual Turn in IR: Documentary Filmmaking as a Critical Method', Millenium: Journal of International Studies, Vol. 43, No. 3 (2015), pp. 891-910.

56 Akin H. Unver, 'Computational International Relations: What Can Programming, Coding and Internet Research Do for the Discipline?', All Azimuth, http://www.allazimuth.com/wp-con tent/uploads/2019/01/Unver_Computational_IR.pdf.

57 For example, Andrew Bennett, 'Found in Translation: Combining Discourse Analysis with Computer Assisted Content Analysis', Millenium: Journal of International Studies, Vol. 43, No. 3 (2015), pp. 984-97; Roland Bleiker, 'Pluralist Methods for Visual Global Politics', Millenium: Journal of International Studies, Vol. 43, No. 3 (2015), pp. 872-90; Judith A. Tickner, 'Dealing with Difference: Problems and Possibilities for Dialogue in International Relations', Millennium: Journal of International Studies, Vol. 39, No. 3 (2013), pp. 607-18.

58 Stephen Chan, Peter Mandaville and Roland Bleiker, eds., The Zen of International Relations: IR Theory from East to West (New York: Palgrave, 2001). 
Ultimately, students and scholars of IR alike should be guided towards a higher level of consciousness about the importance of methodology, and towards an awareness of the need to learn the art of methodology in conducting scholarly inquiry. Members of periphery IR communities like that in Turkey should be encouraged to see the mastering of 'methodological art' as a valuable and rewarding part of their professional development. Since such a change in community values logically begins with the faculty members, a pragmatic starting point is that of appealing to their extrinsic motivation-e.g. acknowledging methodology training and development efforts as being as valuable a part of overall professional activity as speaking at conferences or serving on journal editorial boards and so on, and rewarding them accordingly.

Additionally, the leading Turkish IR journals-and others in the peripherythat are expected to serve as the platform for scholarship production should focus more decisively on methodological quality in their manuscript reviewing and selection processes. Doing so clearly requires first reaching some kind of consensus on what constitutes 'quality', as regards the various applications of methods or methodological approaches. A starting point for doing so is through open discussion. Editors of the leading journals could launch such discussion and encourage genuine, ongoing debate on the topic by occasionally setting aside special issues devoted exclusively to methodology.

Finally, for the purposes of dialogue, leading IR associations in countries like Turkey could organise not just methods-related panels at conferences, but entire workshops on methodological issues which could serve as both mediums for discussion of methods-related debates and actual training workshops. Outside of conference venues, local organisations could serve the community and promote quality methodology by organising summer 'methods' camps for IR students.

\section{Conclusion}

For the good of the Turkish IR disciplinary community, periphery IR, and the global IR discipline as a whole, a local focus on methodological quality and on training in the 'art' of methodology is needed. This call does not aim to promote any particular methodological tools or approaches, nor does it intend to embrace any ontological or epistemological positioning over another. Rather, it seeks to support a re-evaluation of the overall role of methodology in disciplinary training and study in the field of IR, and to recommend greater appreciation of the importance of methodological quality, both for building up tlocal disciplinary communities and for better enabling core-periphery communication.

With methodology and methods serving as a common language between the periphery and core, we may also take a positive step towards addressing the issue of the dominance of English-medium journals in recognised lists of indexed publications, thus allowing greater access to publications and a more powerful voice for periphery scholars. Journal editors and reviewers may find it harder to reject submissions that exhibit robust, high-quality methodologies, even if they do need English language editing, than fluently written pieces with 
weak methodology. Ultimately, the broad-ranging benefits of a focus on improving methodological quality in periphery scholarship could contribute to the aims of the many scholars over past decades that have noted, been dismayed by, and sought to correct the imbalance in knowledge production between core and periphery scholars in IR. 